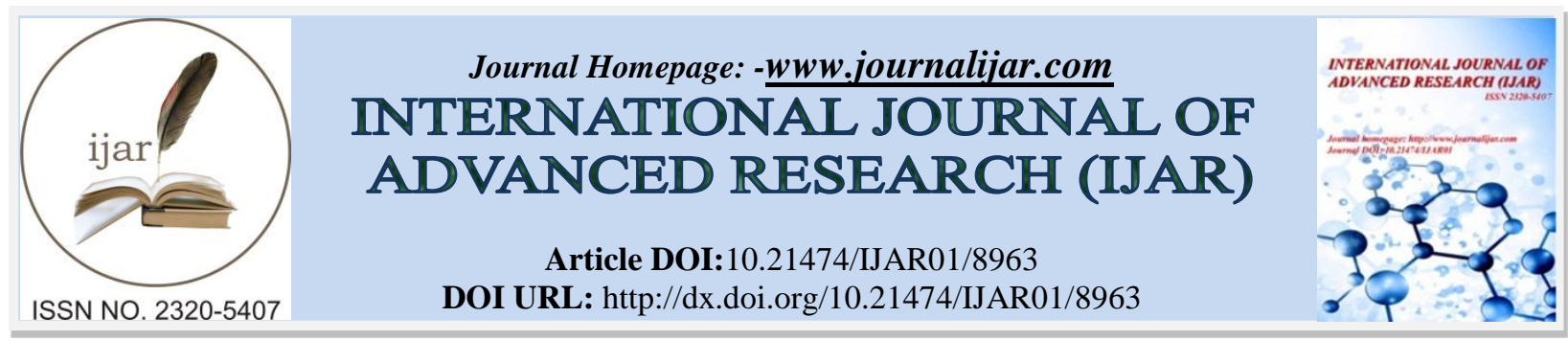

RESEARCH ARTICLE

\title{
THE RELATIONSHIP OF INJURY AND INJURY ASSOCIATED RISK FACTORS IN ETHIOPIAN PREMIER LEAGUE FOOTBALL PLAYERS.
}

Biruk Amare Sorate ${ }^{1}$ and Paramvir Singh ${ }^{2}$.

1. PhD Research Scholar at Department of Sport Sciences, Faculty of Medicine, PUP. and Assistant Professor at Department of Sport Sciences, Jimma University, Ethiopia.

2. Professor Department of Sport Sciences, Faculty of Medicine, PUP.

\section{Manuscript Info}

\section{Manuscript History}

Received: 22 February 2019

Final Accepted: 24 March 2019

Published: April 2019

Key words:-

Football, Incidence, Injury and Risk Factors.

\begin{abstract}
The purpose of this study was to show the relationship of injury and injury associated Risk Factors in Ethiopian Premier League Football Players. A prospective cohort study design was employed. 469 male football players from 16 teams of Ethiopian premier league participated using censuses method. FIFA Medical Assessment and Research Centre form used in order to record information about the players, injuries sustained in training sessions and matches during the competitive season. Data was analysed using descriptive and Pearson product moment correlation statistics. The significance level was set at $\mathrm{p}<0.05$. The most predominant injury was strain, the maximum numbers $(55 ; 37.2 \%)$ occurred on midfield players, followed by strikers $(44 ; 29.7 \%)$, defensive players $(43 ; 29.1 \%)$ and goalkeepers $(6 ; 4 \%)$. The second predominant injury was sprain, highly occurred in defensive players $(21 ; 42 \%)$, and followed by midfield players $(16$; $32 \%)$, strikers $(10 ; 20 \%)$ and goalkeepers $(3 ; 6 \%)$. Injured body part has a significance positive correlation with age $\left(r=0.109, r^{2}=0.012, P\right.$ $<0.021)$ at $\mathrm{P}<0.05$, a significance inverse correlation with height $(\mathrm{r}=$ $\left.-0.154, \mathrm{r}^{2}=0.024, \mathrm{P}<0.002\right)$ at $\mathrm{P}<0.01$ and also the same result was observed with playing position $\left(\mathrm{r}=-0.228, \mathrm{r}^{2}=0.052, \mathrm{P}<0.000\right)$ at $\mathrm{P}$ $<0.01$. The highest prevalence of injury was observed in the middle age, in normal BMI and in outfield players. The midfielders sustained the higher strain injury. The defensive players have higher rates of sprain injury. A significance positive relationship has observed between injured body part and age, height and playing positions, however, insignificance result was observed with injury rate/type. While, inverse significance correlation was observed between injury rate/type and playing position. Therefore, the coaching and medical staffs from football clubs must be emphasize the biological or physiological and psychological characteristics of the players and inadequate rehabilitation after injury to minimize the injury occurred with associated risk factors through improved program for training and fitness evaluation.
\end{abstract}

Copy Right, IJAR, 2019,. All rights reserved. 


\section{Introduction:-}

Football is the popular sport in the world with a great benefit of health, while it's not free from the risks of injury. Football injuries involve predominantly on the lower extremities counting the knee and ankle joints and muscles of the lower limb (Peterson et al., 2000), subsequently the lower extremities in most sports used as locomotive power and speed to the whole body. When all sports are considered the lower extremities are often at an overall greater risk of injury than central (back, neck and head) and upper extremities (Hutchinson and Nasser, 2000). Injuries occurred in football are traumatic, which are $57.8 \%$ in match and in training are $42.2 \%$; it is caused by body contacts (Powell and Barber-Foss, 2000).

The risk factors of injury can be categorized under the internal and external risk factors (Dvorak et al., 2000). The biological or physiological and psychological characteristics of a person like age, joint mobility, functional stability, biomechanical and anatomical characteristics, previous injuries and inadequate rehabilitation after injury are affected by direct contact are considered as internal factors of injury. In the development of lower limb muscle injuries the most commonly associated risk factor is nonexistence of muscle flexibility (Witvrouw et al. 2001; Witvrouw et al. 2004).

Football players maturity levels are an intrinsic injury risk factor might affect the performance in football. Early maturing football players are favored, whereas, late maturing elite football players tends to exclude. Muscle strength, aerobic capacity, speed and coordination fitness must have rationally in a high level (Giza and Micheli, 2005). Injured players in such cases like, syndesmotic and medial ankle sprains have higher body mass index than uninjured players. This can show that there is the association between body mass index and lower extremities injury like ankle sprains (Waterman, et al., 2011). Players are more disposed to non-contact ankle sprains in football injury, if they are in increased body mass index $>23.1 \mathrm{~kg} / \mathrm{m}^{2}$ and their body weight is $>72.6 \mathrm{~kg}$ (Fousekis, et al., 2012).

A specific relationship between injury and player position has been referred as the greater the activity and covered distance during matches, the higher the risk of injury (due to increased acceleration/deceleration activity) (Bahr \& Holme, 2003 and Árnason, et al, 2004). Different positional roles implicate different playing characteristics. Defenders tend to "tackle hard", strikers are intended to strike the ball into goal, and wingers are known for their running (Azubuike \& Okojie, 2009). Therefore, there is a need for study the association of injury and injury associated risk factors throughout the competitive season, in Ethiopian premier league level registered male football players.

\section{Materials And Methods:-}

The study was conducted in Ethiopian premier league football clubs. A prospective cohort study design was employed throughout the competitive season.

\section{Subjects}

Four hundred and sixty nine male football players from 16 teams of Ethiopian premier league was participated using censuses method. The players were well informed about the aim and the design of the study prior to the study; they engaged a verbal informed consent for participation.

\section{Data Collection Instrument}

The data collection instruments for this study were; FIFA Medical Assessment and Research Centre (F-MARC's) form was used in order to record information about the players, injuries they sustained, regarding training sessions and matches during the competitive season. For injury a short and simple report form was used to record information regarding injuries (Fuller, et al., 2006).

\section{Methods of Data Analysis}

Data was analyzed using descriptive statistics, such as mean \pm SD, frequency, percentage, descriptive and cross tabulation. Pearson product moment correlation was used to identify injury associated Risk Factors (age, height, weight, BMI, and playing position). Pearson product moment correlation was used to identify injury associated Risk Factors. The significance level was set at $\mathrm{p}<0.05$. The statistical analysis was done by SPSS version 23 software.

\section{Result And Discussion:-}

The players injury patterns presented with age categories in figure 1 . The maximum $(171 ; 48.7 \%)$ injury was occurred in the age categories of 26 to 30 years old, followed by 21 to 25 years old (107; 30.3\%), 31 to 35 years old 
$(66 ; 18.8 \%)$ and the lowest injury was occurred in 16 to 20 years old $(7 ; 2 \%)$. From the result of this study the researchers can understand that the highest prevalence of injury was observed in the middle age of the players. In line with the current finding there was a trend toward a higher injury rate in the 26 to 34 year-old age group (Webborn, et al., 2016). While, the finding other studies showed that the older players are more prone to injury (Ostenberg \& Roos, 2000; Arnason, et al., 2004; Hagglund, et al., 2013).

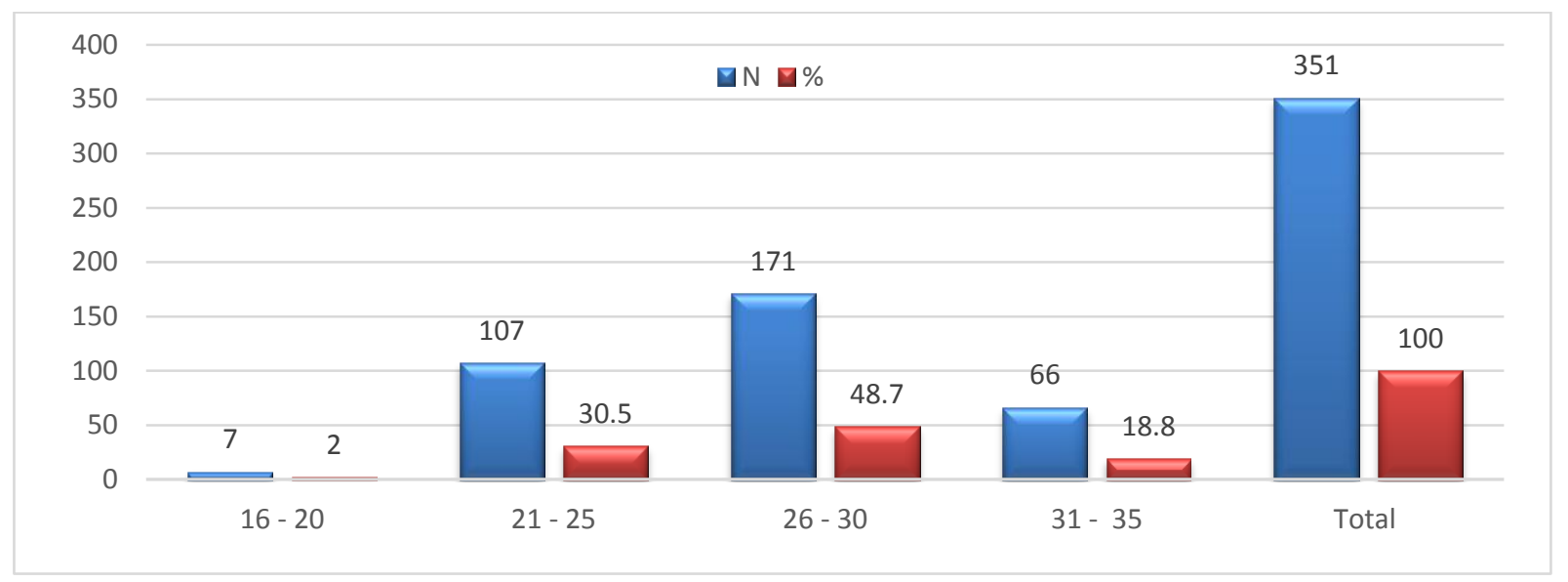

Figure 1:-Injury pattern by age categories

Figure: 2, presented the injury patterns according to BMI. The maximum injury was occurred in the normal (18.5 24.9) BMI of the players $(331 ; 94.3 \%)$, followed by over weight $(25-29.9)$ BMI $(18 ; 5.1 \%)$ and the lowest injury was occurred in the underweight $(<18.5)$ BMI $(2 ; 0.6 \%)$, but injury was not occurred in the BMI of 30 and above. From the result we can understand that, high rate of injury was occurred in the normal BMI. In contrast with this study, the previous study showed that the prevalence of overweight or obesity was markedly higher among injured football players $(54.4 \%)$ than among athletes of any other sport (Yard, and Comstock, 2011).

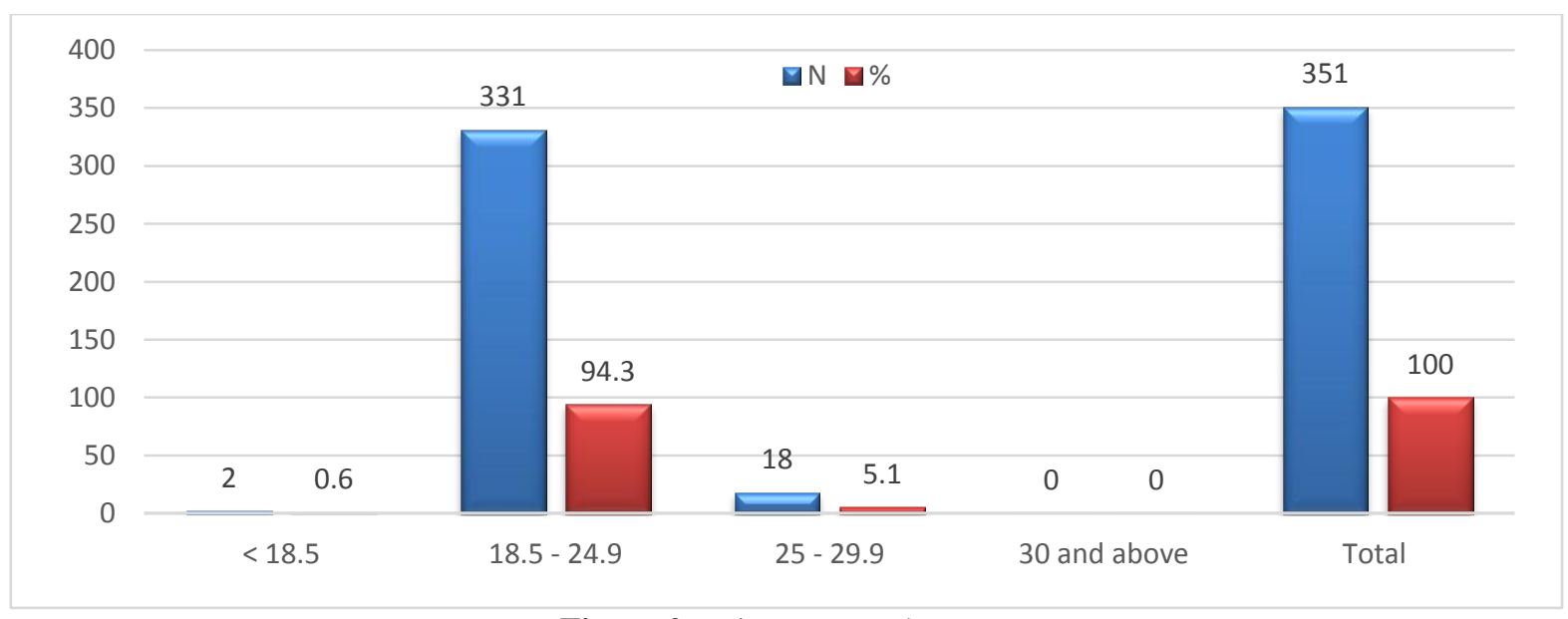

Figure 2:-Injury pattern by BMI

Figure: 3 , illustrated that the injury pattern according to the players playing positions. The prevalent injured playing position was defensive players $(118 ; 33.6 \%)$, followed by midfielders $(112 ; 31.9 \%)$, striker $(92 ; 26.2 \%)$, and goalkeepers $(29 ; 8.3 \%)$. The result indicates that the maximum number of injury was occurred in defensive and midfield players. In opposite of this study, the previous finding of epidemiological study indicated that the greater prevalence of sports injuries was occurred in strikers (Carling, et al., 2010; Fachina, et al., 2013; Onaka, et al., 2017), while another study shown that equivalent prevalence of injury among all soccer positions (Dauty and Collon, 2011). 


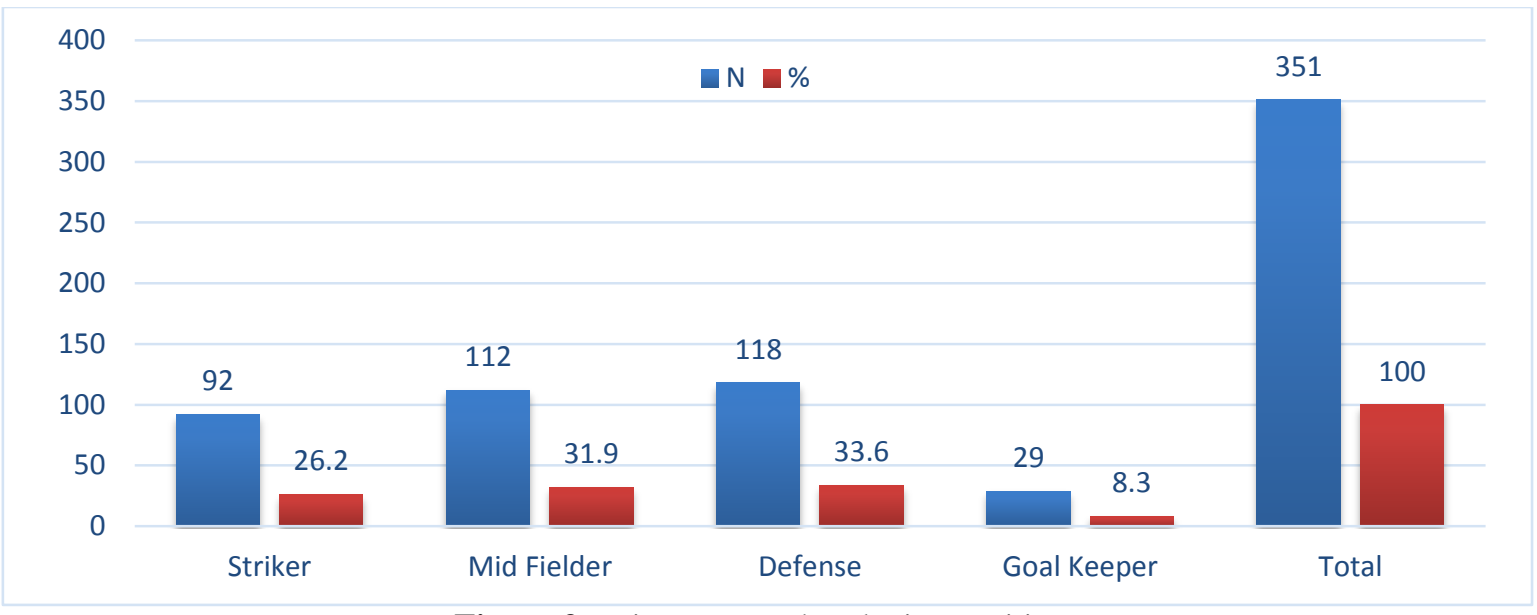

Figure 3:-Injury pattern by playing positions

As presented in table 1 , the most predominant occurred injury was strain in a total of 148 injuries all playing positions, while midfield players sustained the maximum numbers of strain $(55 ; 37.2 \%)$, followed by strikers (44; $29.7 \%)$, defensive players $(43 ; 29.1 \%)$ and goalkeepers $(6 ; 4 \%)$. This indicated that outfield players sustained strain more than the goalkeeper and from outfield players midfield players have higher strain injury. The second predominant injury was sprain, highly occurred in defensive players $(21 ; 42 \%)$, and followed by midfield players $(16 ; 32 \%)$, strikers $(10 ; 20 \%)$ and goalkeepers $(3 ; 6 \%)$. The finding of this study showed that, defensive players have higher rates of sprain injury, supported with other study which is there was no differences found between outfield players' injury rates (Kristenson, 2015). Even though, strain and sprain were predominantly occurred injuries in outfield players, supported with previous studies of football players (Haxhiu, et al., 2015; Emery, et al., 2005; Hawkins, et al., 2001). In contrast, the goalkeepers have lower injury rates than outfield players. In line with this finding previous studies indicated that, goalkeepers were found to have a lower injury rate than outfield players (Aoki, et al., 2012; Árnason, et al., 2004b; Ryynänen, et al., 2013). While, concussion (head) injury rate was higher than outfield players. In with this study, goalkeepers were found to have a higher rate of head injuries (Kristenson, 2015).

Table 1:-Injury pattern by playing positions

\begin{tabular}{|c|c|c|c|c|c|}
\hline Injury pattern in PP & Striker & Midfielder & Defense & Goal Keeper & Total \\
\hline Concussion & 0 & 0 & 1 & 3 & 4 \\
\hline Fracture & 2 & 1 & 8 & 2 & 13 \\
\hline Dislocation & 1 & 2 & 7 & 1 & 11 \\
\hline Muscle Fiber Rupture & 3 & 0 & 4 & 0 & 7 \\
\hline Tendon Rupture & 0 & 0 & 2 & 0 & 2 \\
\hline Ligamentous rupture & 5 & 3 & 4 & 1 & 13 \\
\hline Lesion of meniscus & 6 & 3 & 8 & 2 & 19 \\
\hline Sprain & 10 & 16 & 21 & 3 & 50 \\
\hline Strain & 44 & 55 & 43 & 6 & 148 \\
\hline Contusion & 3 & 9 & 2 & 2 & 16 \\
\hline Bursitis & 6 & 11 & 8 & 1 & 26 \\
\hline Tendinitis & 8 & 8 & 3 & 0 & 19 \\
\hline Laceration / Abrasion & 1 & 2 & 4 & 5 & 12 \\
\hline Others & 3 & 2 & 3 & 3 & 11 \\
\hline Total & 92 & 112 & 118 & 29 & 351 \\
\hline
\end{tabular}

As indicated in table 2 injured body part has a significance positive correlation with age $\left(\mathrm{r}=0.109, \mathrm{r}^{2}=0.012, \mathrm{P}<\right.$ $0.021)$ at $\mathrm{P}<0.05$, a significance inverse correlation with height $\left(\mathrm{r}=-0.154, \mathrm{r}^{2}=0.024, \mathrm{P}<0.002\right)$ at $\mathrm{P}<0.01$ and also the same result was observed with playing position $\left(\mathrm{r}=-0.228, \mathrm{r}^{2}=0.052, \mathrm{P}<0.000\right)$ at $\mathrm{P}<0.01$. Insignificance result was also observed between injury rate/type with age, height, weight and BMI of the players. The study conducted on risk factors for injuries in professional football players was shows that strong association 
observed between age and injury incident (Haxhiu et al., 2015). Age might affect IR in some cases, but in some cases, no association between age and injury risk in general has been found (Hagglund, et al., 2006; 2009) and also another finding indicates there was no significant relationship between age with injury rate (Soheil, and Hassan, 2018). The studies indicated that, Body mass index were not related to injuries, which is in accordance with the previous studies on adult players (Ostenberg and Roos, 2000; Beynnon, et al., 2001). While, weak negative significance correlation was observed between types of injury and playing position $\left(r=-0.132, r^{2}=0.017, P<\right.$ $0.013)$ at $\mathrm{P}<0.05$. The result supported with the study indicated a specific relationship between injury and player position has been referred (Giza and Micheli, 2005).

Table 2:-Relationship of Injury with Age, Ht, Wt, BMI and Playing Positions

\begin{tabular}{|l|l|c|c|}
\hline \multicolumn{2}{|l|}{ Age } & Injured Body Part & Injury Rate/Type \\
\cline { 2 - 4 } & Searson Correlation & $\mathbf{0 . 1 0 9}$ & -0.028 \\
\hline \multirow{2}{*}{ Height in meter } & Pearson Correlation & 0.021 & 0.599 \\
\cline { 2 - 4 } & Sig. & $\mathbf{- 0 . 1 5 4}^{* * *}$ & -0.032 \\
\hline \multirow{2}{*}{ Weight in Kg } & Pearson Correlation & 0.002 & 0.548 \\
\cline { 2 - 4 } & Sig. & -0.043 & -0.021 \\
\hline \multirow{2}{*}{ PMI } & Pearson Correlation & 0.212 & 0.691 \\
\cline { 2 - 4 } & Sig. & -0.033 & -0.074 \\
\hline \multirow{2}{*}{$* *$ Correlation is significant at the 0.01 level. } & 0.269 & 0.167 \\
\cline { 2 - 4 }$*$ Position & Pearson Correlation & $\mathbf{- 0 . 2 2 8}$ & 0.013 \\
\hline
\end{tabular}

\section{Conclusion:-}

Based on the results the following points were concluded. The highest prevalence of injury was observed in the middle age, in the normal BMI and in defensive and midfield players. The outfield players sustained strain more than the goalkeeper and from outfield players midfield players have higher strain injury. While, the defensive players have higher rates of sprain injury. A significance positive relationship has observed between injured body part and age, height and playing positions, insignificance result was also observed between injury type with age, height, weight and BMI of the players. While, negative significance correlation was observed between injury type and playing position.

Therefore, based on the above finding, the researchers suggested that, coaching and medical staffs from football clubs must be emphasize the biological or physiological and psychological characteristics of the players like age, functional stability and anatomical characteristics (weight, height and BMI), and inadequate rehabilitation after injury considered as internal factors of injury to minimize the injury occurred with associated risk factors through improved program for training and fitness evaluation.

\section{Acknowledgements:-}

to all participants, coaches and medical staff of clubs.

\section{Conflict of interest:}

The authors declare that they have no conflict of interest.

\section{References:-}

1. Aoki, H., O’Hata, N., Kohno, T., Morikawa, T., \& Seki, J. (2012). A 15-year prospective epidemiological account of acute traumatic injuries during official professional soccer league matches in Japan. The American journal of sports medicine. 40(5), 1006-1014.

2. Arnason A, Sigurdsson SB, Gudmundsson Á, Holme I, Engebretsen L, Bahr R, (2004). Risk factors for injuries in football, Am J Sports Med; 32(1 Suppl):5S-16S.

3. Árnason Á, Tenga A, Engebretsen L, et al. (2004b). A prospective video-based analysis of injury situations in elite male football: football incident analysis. Am J Sports Med. 32(6):1459-1465.

4. Azubuike SO, Okojie OH., (2009). An epidemiological study of football (soccer) injuries in Benin City, Nigeria. Br J Sports Med. May; 43(5):382-6. 
5. Bahr R, Holme I. (2003). Risk factors for sports injuries---a methodological approach. Br J Sports Med; 37(5):384-92.

6. Beynnon BD, Renstrom PA, Alosa DM, Baumhauer JF, Vacek PM. (2001). Ankle ligament injury risk factors: a prospective study of college athletes. J Orthop Res. 19:213-20.

7. Carling C, Orhant E, LeGall F. (2010). Match injuries in professional soccer: inter-seasonal variation and effects of competition type, match congestion and positional role injury in professional soccer. Int J Sports Med. 31(4):271-6.

8. Dauty M, Collon S. (2011). Incidence of injuries in French professional soccer players. Int J Sports Med. 32(12):9659.

9. Dvorak J, Junge A, Chomiak J, et al. (2000). Risk factor analysis for injuries in football players. Possibilities for a prevention program. Am J Sports Med; 28 (suppl5):S69-74.

10. Emery CA, Meeuwisse WH, Hartmann SE. (2005). Evaluation of risk factors for injury in adolescent soccer. Implementation and validation of an Injury Surveillance System. Am J Sports Med. 33(12): 1882-91.

11. Fachina RJFG, Andrade MS, Silva FR, Waszczuk Junior S, Montagner PC, Borin JP, et al. (2013). Descriptive epidemiology of injuries in a Brazilian premier league soccer team. Open Access J Sports Med. 4:171-4.

12. Fousekis, K., Tsepis, E., \& Vagenas, G. (2012). Intrinsic risk factors of noncontact ankle sprains in soccer: a prospective study on 100 professional players. The American journal of sports medicine, 40(8), 1842-1850.

13. Fuller CW, Ekstrand J, Junge A, Andersen TE, Bahr R, Dvorak J et al. (2006). Consensus statement on injury definitions and data collection procedures in studies of football (soccer) injuries. Br J Sports Med; 40(3):193-201.

14. Giza E, Micheli LJ. (2005). Soccer injuries. Med Sport Science; 49:140-69.

15. Hagglund M, Walden M, Ekstrand J. (2013). Risk factors for lower extremity muscle injury in professional soccer: the UEFA Injury Study. Am J Sports Med. 41(2):327-35.

16. Hagglund M, Walden M, Ekstrand J. (2009). UEFA injury study--an injury audit of European Championships 2006 to 2008. Br J Sports Med. 43(7):483-9.

17. Hagglund M, Waldén M, Ekstrand J, (2006). Previous injury as a risk factor for injury in elite football: A prospective study over two consecutive seasons, Br J Sports Med; 40(9):767-772.

18. Haxhiu B, Murtezani A, Zahiti B, Shalaj I, Sllamniku S. (2015). Risk Factors for Injuries in Professional Football Players. Folia Medica. 57(2): 138-143.

19. Hawkins RD, Hulse MA, Wilkinson C, Hodson A, Gibson M. (2001). The association football medical research programme: an audit of injuries in professional football. Br J Sports Med. 35(1):43-7.

20. Hutchinson M.R. and Nasser R (2000). Common sports injuries in children and adolescents. Medscape General Medicine 2(4)

21. Kristenson, K. (2015). Risk factors for injury in men's professional football. British Journal of Sports Medicine, 50(11), 699-702.

22. Onaka, G. M., Gaspar-Jr, J. J., Graças, D. D., Barbosa, F. S. S., Martinez, P. F., \& Oliveira-Junior, S. A. D. (2017). Sports injuries in soccer according to tactical position: a retrospective survey. Fisioterapia em Movimento, 30, 249 257.

23. Ostenberg A, Roos H. (2000). Injury risk factors in female European football. A prospective study of 123 players during one season. Scandinavian Journal of Medicine \& Science in Sports. 10:279-85.

24. Peterson L, Junge A, Chomiak J, Graf-Baumann and Dvorak J. (2000). Incidence of football injuries and complaints in different age groups and skill levels. American Journal of Sports Medicine 28(5):S51-57.

25. Powell JW and Barber-Foss KD (2000). Sex related patterns among selected high school sports. American Journal of Sports Medicine 28(3):385-91.

26. Ryynänen J, Junge A, Dvorak J. (2013). The effect of changes in the score on injury incidence during three FIFA World Cups. Br J Sports Med. 47(15):960-964.

27. Soheil, H., \& Hassan, D. (2018). A Prospective Study on the Relationship between Sports Injuries and some of the Physical Fitness Factors in Soccer Players. Journal of Physical Education, Health and Sport, 5(1), 14-20.

28. Waterman BR, Belmont PJ, Jr., Cameron KL, Svoboda SJ, Alitz CJ, Owens BD. (2011). Risk factors for syndesmotic and medial ankle sprain: role of sex, sport, and level of competition. Am J Sports Med; 39(5):992-8.

29. Webborn, N., Cushman, D., Blauwet, C. A., Emery, C., Derman, W., Schwellnus, M., Stomphorst, J., Van de Vliet, P.V. \& Willick, S. E. (2016). The epidemiology of injuries in football at the London 2012 Paralympic Games. PM\&R, 8(6), 545-552.

30. Witvrouw E, Danneels L, Asselman P, D'Have T and Cambier D (2001) Muscle flexibility as a risk factor for developing muscle injuries in male soccer players. The American Journal of Sports Medicine 31(1):41-46.

31. Witvrouw E, Mahieu N, Danneels L and McNair P (2004). Stretching and injury prevention: an obscure relationship. Sports Med 34(7):443-339.

32. Yard, E., \& Comstock, D. (2011). Injury patterns by body mass index in US high school athletes. Journal of physical activity and health, 8(2), 182-191. 